\title{
Experiential Qualities of Whispering with Voice Assistants
}

\author{
Emmi Parviainen \\ KTH Royal Institute of Technology \\ Stockholm, Sweden \\ emmip@kth.se
}

\author{
Marie Louise Juul Søndergaard \\ KTH Royal Institute of Technology \\ Stockholm, Sweden \\ mljso@kth.se
}

\begin{abstract}
We present a Research through Design project that explores how whispering influences the ways people experience and interact with voice assistants. The research project includes a co-speculation workshop and the use of a design probe, which culminated in the production of a design fiction short film. Our design-led inquiry contributes with experiential qualities of whispering with voice assistants: creepiness, trust, and intimacy. Furthermore, we present how whispering opens up new dimensions of how and when voice interaction could be used. We propose that designers of whispering voice assistants should reflect on how they facilitate the experiential qualities of creepiness, trust, and intimacy, and reflect on the potential challenges whispering brings to the relation between a user and a voice assistant.
\end{abstract}

\section{Author Keywords}

Whispering; voice assistants; design fiction; research through design; voice interaction; experiential qualities

\section{CCS Concepts}

-Human-centered computing $\rightarrow$ Interaction design theory, concepts and paradigms;

\section{INTRODUCTION}

Since the Industrial and Electrical Revolution, machines have overpopulated the world with sounds [46]. Simultaneously, in Western industrialized societies, volume has been power and people have been showing importance and authority in this volume-war through screams and yells [27]. However, in between loud voices and noisy machines, is a voice that is impossible to kill. The whispering voice is weak in volume, yet "it touches our innermost emotions and deepest desires" [27]. Whispering is used to communicate various moods, feelings and contexts in human-human interaction, and it challenges the assumption that 'volume is power'. We propose that in the future of voice-enabled intelligent technology, noises made by machines should not be overcome by using more volume. On the contrary, we should find new rich and evocative ways to communicate with technologies drawing on how humans express themselves through whispering.

Permission to make digital or hard copies of part or all of this work for personal or classroom use is granted without fee provided that copies are not made or distributed for profit or commercial advantage and that copies bear this notice and the full citation on the first page. Copyrights for third-party components of this work must be honored. For all other uses, contact the owner/author(s).

CHI'20, April 25-30, 2020, Honolulu, HI, USA

(C) 2020 Copyright held by the owner/author(s).

ACM ISBN 978-1-4503-6708-0/20/04

DOI: https : //doi.org/10.1145/3313831.3376187

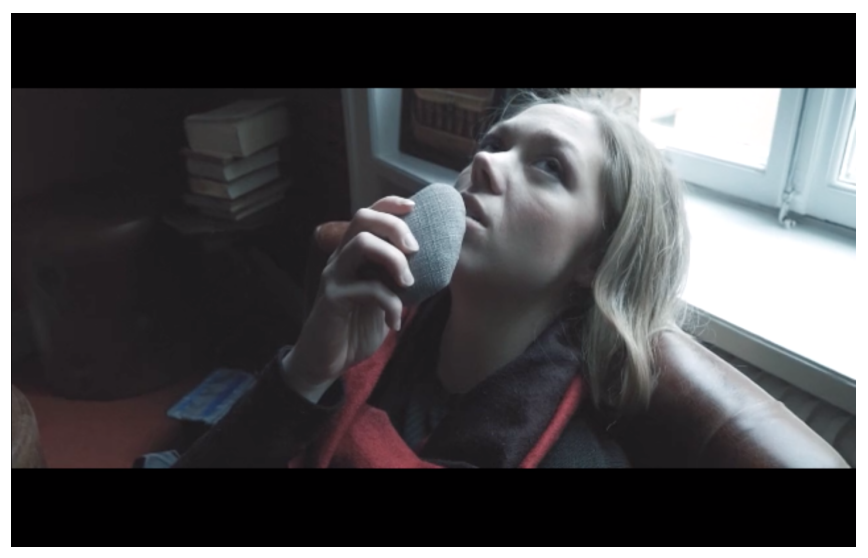

Figure 1. Still shot of the protagonist whispering to a voice assistant.

In late 2018, Amazon introduced a new way to interact with Alexa: a whisper mode [42]. When a user whispers to Alexa, Alexa will whisper back to the user with a lower volume. This allows a user to interact with a voice assistant in contexts where speaking with full volume is not ideal e.g. when there is a sleeping baby in the same room [42]. Both Apple and Microsoft have been granted patents for voice assistants providing whispering speech modes. In contrast to Amazon Alexa and Apple who both propose that whispering is useful in situations where a user does not want to disturb people around them, Microsoft sees whispering as a solution for communicating private information in public spaces [29]. Despite technology companies highlighting the useful property of whispering, users of Alexa began to label the behavior as "creepy" [18]. One reason being that whispering pushes against the traditional social norms of a machine-like voice assistant [54]. Consequently, to release the possible potential of whispering voice assistants, it is crucial to understand how current social norms of whispering challenge and correspond with the social norms of voice assistants.

To explore how whispering influences how people experience voice assistants, we carried out a Research through Design (RtD) project. We used design fiction methods, such as a co-speculation workshop and a production of a short film, to inquire the future opportunities and challenges of using whispering as a voice modality in voice assistants. We contribute by proposing a series of dimensions and experiential qualities of whispering with voice assistants. The dimensions and experiential qualities can be used analytically to better understand shifting social norms of voice assistants, and generatively to design new experiences of whispering voice assistants. 


\section{RELATED WORK}

In the following sections, we present related work on voice assistants and whispering. We describe the framework of implicit interaction since it allows us to better understand and speculate on how the voice modality of whispering can be used to implicitly interact with voice assistants. Lastly, we describe the characteristics of whispering.

\section{Voice Assistants}

Voice assistants are characterized by being conversational user interfaces (CUI): an interface through which a user can interact with a computer by having a conversation [48]. The primary design materials of a voice assistant include the computer generated speech $[34,35,52]$, the perceived persona or personality of the assistant [26], the algorithms executing the "conversation" and informational data accessed and stored through the Internet. Voice assistants can be embedded in a range of objects, such as speakers, smartphones, watches, TV remotes, headsets and rings. In HCI, there is an increasing amount of research done on how people use and understand voice assistants $[39,48]$. Research has shown that the use of voice assistants is often initiated with excitement and exploration, after which the limitations slowly come across and a few use cases turn into routines [48]. Voice assistants are often used in the home, embedded in smart speakers that are placed in bedrooms, living rooms and kitchens [48]. The three most frequently used command categories are found to be (1) Music; (2) Search; and (3) IoT control commands [1]. In the home, voice assistants can improve productivity through coordination and multi-tasking functionalities, e.g. freeing up the hands to do other tasks while scheduling a calendar, adding to a shopping list, setting a timer etc. [51]. Voice assistants are also social actors [35] and contribute to enjoyment in the home, as people are having "fun" with their voice assistants; making jokes, dancing, impressing guests, and perceiving them as "best friends" and "helping hosts" [51]. The "fun" of voice assistants are also reflected in studies on children's use of voice assistants [7]. While voice assistants have numerous advantages, research also points to further improvements of voice assistant design, such as how assistants could actively offer new features to users, or leverage knowledge of the place they are used to give specific responses or support particular action [48]. Porcheron et al. have argued that voice assistants are not conversational, but rather build on requests/responses and that this skews expectations to the conversation [39]. Reeves argues that HCI should not aim to solve "bad" conversations by technological improvements [44]. Rather, instead of talking about "conversational design", Reeves proposes "conversationsensitive design" pointing to how CUIs fit into and around conversation [44].

Design research is capable of attending to and shaping our conceptual understandings of voice assistants, including their social norms and ideologies. We build on design fiction research with voice assistants focusing on social dimensions, such as work by Søndergaard and Hansen that explored how voice assistants are gendered [50], and Rogers et al's work on a healthier voice-enabled Internet [45]. Findings from Søndergaard and Koefoed Hansen [50] suggest a future where a voice assistant does not invent new individual needs, but rather support social issues, enable matters of care, trust and interdependency. In "Our Friends Electric", Rogers et al.'s also work on conflicts of privacy and trust and propose that design advocacy can be initiated through design fiction short films [45]. Recently, it was highlighted that trust is a critical part of voice interaction, calling for measures on how researchers evaluate trust [8]. We build on this design research and inquiry deeper into dimensions of trust and how social norms are shaped through our interactions with voice assistants.

\section{Implicit Interaction}

Voice assistants are part of current conceptual visions of future technologies, such as faceless interaction [20] and implicit interaction [22]. Faceless interaction refers to interactions that transcend traditional surface-based interfaces, such as screens. This includes interaction through voice, gestures or body movement [20]. Implicit interaction characterises communications between a user and a machine which are made without explicit input or output; e.g. if an exchange is made outside the attentional foreground of the user or if the exchange is initiated by the computer [22]. Research has focused on exploring systems that act based on user movements and proximity [16, 2], as well as systems that could identify emotions such as anxiety and respond to it accordingly [41].

In human face-to-face interaction, a lot of the daily interaction is made implicitly [47]. Interaction with voice assistants is still, however, strongly explicit: they only respond when a user explicitly demands information or an action. Consequently, interaction with a voice assistant is processed through the literal meaning of the words while discarding factors such as voice modalities, body language and context of speech; factors that are vital for human-human interaction [28]. The way of borrowing components from human interaction and applying them to HCI has existed in the field for a long time. Proxemics is Edward Hall's theory of these interpersonal spatial relationships [16] and presents the use of proxies when designing for intelligent environments. Proxemics is relevant to whispering since whispering requires a person and another person or an assistant to be in close proximity to each other for it to be heard. Besides proxemics, different voice modalities play a significant role in human-human interaction. By the tone of their voice, people can communicate their mood such as happiness or uncertainty as well as the context of information. Herbert H. Clark [5, 17] argues how language is indeed communication between non-linguistic as well as linguistic signals and always involves the speaker's meaning and the addressee's understanding of it. Voice assistants today do not implicitly match or adapt to the user's speech modality. A shout does not get a shout back nor does a cry for a mental health line get more than a response with a Clippy-like enthusiasm. Whispering is the first attempt to implicitly interact with voice assistants using a distinct voice modality to adapt to the social and emotional context.

\section{Whispering}

Human's understanding of vocalised voice perception comes from the emotion recognition of human-human interaction. Whispering as voice modality could, therefore, be used to communicate emotions and context the same way we reveal 
emotions like anxiety or fear through the tone of our voice instead of words.

Whispering (or 'unvoiced speech') that uses an unvoiced mode of phonation, is a frequent voice modality among humans. Xinghua Li [27] challenges the assumption of 'volume is power', and argues that whispering communicates emotions like intimacy, affection and desire but also uncertainty and fear. Whispering imprints the values of domesticity and femininity, but in public places, whispering turns sour since a lowered voice is connected to gossiping and disconnecting others from private conversations [27]. We might speculate: Is whispering doomed to only stay between lovers or parents and children, or could whispering become a common way of interacting between humans and computers? What intentions can we communicate through whispering and how would it affect implicit interaction and the decision making for us?

In this paper, we speculative on how whispering could potentially build a deeper relationship between humans and computers; what new design opportunities whispering brings to concrete situations, and what potential challenges it may hold in our perception of voice assistants and own everyday life.

\section{WHISPERING FUTURES: DESIGN PROCESS}

In this section, we describe our design research process in details and with transparency to make it clear how design practice contributed to framing our general research purpose of exploring whispering as a novel and evocative voice modality to communicate with a voice assistant.

We follow a research through design methodology [12] to allow the research a holistic and experience-based approach based on design-led inquiry. We present the process and the outcome with the aim of focusing on how particular design decision became embedded in the final artefact. Our RtD process follows a methodological commitment to producing futureoriented, aspirational and generative design knowledge driven by practice, that is able to creatively challenge status quo thinking [43]; in this case on the subject of whispering voice assistants. Our process evolved through auto-ethnographic experiences [31] with whispering to a Google Home and whispering with Amazon Alexa, a co-speculation workshop that explored whispering as an interaction mode, and the use of a design probe which culminated in the production of a design fiction short film.

We used design fiction methods to produce design knowledge that can inspire the future design of voice assistants and to anticipate possible consequences of future voice technologies. Design fiction is a critical and speculative method is capable of addressing future situated practices with technology and the personal affective experiences and dilemmas this may bring [32]. The use of stories can be a way to envision new futures, both from the technical and social point of view, but also a way to communicate innovations and possible risks to others $[53,4]$. Design fiction has previously been used to explore the design and sociotechnical imagining of voice assistants [50, 45]. We build on these uses of short films to represent design fictions with a particular focus on how stories and narratives can open reflections about the technology-mediated relation between the short film's protagonists: the human and the voice technology [36].

\section{Co-speculation Workshop}

We began this project by co-speculating the effects of whispering, why we whisper, and how it could be used as an interaction mode in the future. Speculating on futures, bounded by our individual experiences and social points of view, requires a set of minds to co-speculate [6] to combine different perspectives into particular possible futures. To explore the future of whispering voice assistants, we conducted a 2-hour co-speculation workshop.

\section{Pilot study}

To make sure that the co-speculation workshop would prompt speculation and collect evocative ideas, we carried out two pilot studies. The first pilot study involved four participants (two men and two women) and the second one involved one additional female participant. We chose to host the pilot studies in a home environment since it was crucial that the participants considered the context where the voice assistant would be placed along with being able to speculate the use of it. When speculating on whispering as a voice modality, both of the male participants expressed that they never whisper and, therefore, felt uncomfortable doing so. They also suggested it being more bounded by feminine characteristics. To not reproduce the stereotype of whispering being something that mainly women do, it was critical to aim for diverse participation in terms of genders in the following workshop. Before conducting the second pilot study, changes were made from the first pilot study by re-designing exercises to ensure sticking to the theme and fitting the time constraint of the workshop. In addition, to make whispering feel more comfortable for the participants, we added an exercise where the participants could whisper in pairs rather than in a big group. The second pilot study proved to improve the flow of the workshop and keep the participants well informed about the purpose of the different phases of the workshop and how they come together.

\section{Participants}

For the actual co-speculation workshop, we recruited seven participants; four men and three women (Figure 2), from ages of 24 to 48 with nationalities of Sweden, Hungary, Spain and the USA (Table 1). Six of the participants were either users of a voice assistant or worked with voice technology. Six of them were also User Experience (UX) Designers or researched the area of HCI, while one worked with iOS development. These participants were chosen to gain expertise in the voice assistant technology and innovative thinking of how it could be used in the future. Speculating on design proposals based on emerging technologies like voice assistants is a complex challenge and we saw it as an advantage to combine people who had knowledge on and experience with voice assistants.

\section{Data Analysis}

The workshop consisted of an introduction, two self-reflective exercises about whispering and the future of voice assistants, as well as one design challenge of a futuristic use case of a whispering home assistant. A consent form was filled in order to agree to the participation of the workshop and using 
Table 1. Overview of the participants

\begin{tabular}{cccc}
\hline Pseudonym & Role & Nationality & Age \\
\hline Anna & $\begin{array}{c}\text { UX } \\
\text { Designer } \\
\text { HCI }\end{array}$ & HUN & 35 \\
Kate & $\begin{array}{c}\text { Reseacher } \\
\text { HCI } \\
\text { Researcher } \\
\text { OX }\end{array}$ & ES/US & 26 \\
George & $\begin{array}{c}\text { Designer } \\
\text { iOS } \\
\text { developer } \\
\text { Nicklas }\end{array}$ & SWE & 28 \\
Susan & $\begin{array}{c}\text { Designer } \\
\text { UX }\end{array}$ & SWE & 43 \\
& $\begin{array}{c}\text { Designer } \\
\text { SWE }\end{array}$ & 48 \\
& &
\end{tabular}

the data in research. The workshop was documented through mixed media; our data consists of video recordings and photos taken by the authors, in addition to the participants' sketches, notes and concepts, our written field notes, and transcripts of selected quotes from the video. We organized the data by iterative grouping participants' concepts with quotes, mapping out generative insights on participant's current experiences of whispering and future concepts for whispering voice assistants. In the following, we present the structure of the workshop as well as the results of our analysis.

\section{Process}

The workshop began with an introduction to voice assistants, speculative futures, and the goal of the workshop. In order to get the participants to imagine beyond the current voice technology and instead, the future in ten years, the participants were shown a short film Our Friends Electric [45]. This film was chosen due to its storyline that challenges the common assumptions around voice assistants and explores the relationships we might have with increasingly "intelligent" devices. To make the participants reflect on whispering, the workshop included an exercise that required the participants to whisper to each other. The question How does it feel to whisper? was a vital starting point for this workshop.

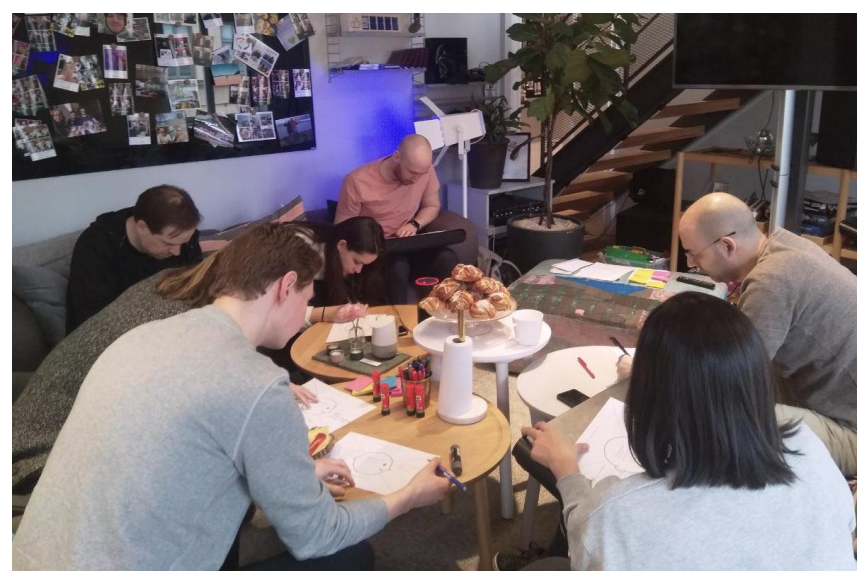

Figure 2. Workshop session was conducted in a comfortable office environment.
The workshop continued with a task that helped with selfawareness and to understand Why do we whisper? The participants were asked to think about occasions where they whisper to friends, family, loved ones, or strangers. This activity made participants ready for ideation. The participants often addressed their whispering mainly to one particular person either a partner, a close friend or a relative. In private situations, the participants described whispering when expressing forms of tenderness or intimacy to their partners or children, or when being sick or too tired to use the full volume of their voice. In public, whispering was preferred to not disturb others, or when intentionally excluding others from a conversation like when telling secrets, gossiping or asking embarrassing questions like "Where is the restroom?" (Anna).

The feelings and emotions that whispering brought up were described as intimate, secretive and even naughty. The participants also described how it could make them feel scared or insecure in a situation or awkward and creepy when whispering in a context where it is not required "It could be creepy if someone whispered me when it's just the two of us" (Oscar) "...or imagine if someone would whisper a laugh" (Kate). Whispering could also make you feel polite and considered when you know that you are not causing disturbance to others but also rude if it leads to excluding others from the conversation or attracting negative notice. In this context, a taboo of whispering was evident and considered impolite.

After reflecting on their own experiences, it was time for an individual speculation and the participants were asked to come up with their whispering home assistant and the interaction with it (Figure 3-4). This assignment imposed questions such as How could whispering to your assistant help your relationship with each other, Why would you whisper to your assistant, and How would whispering to your assistant make you feel?

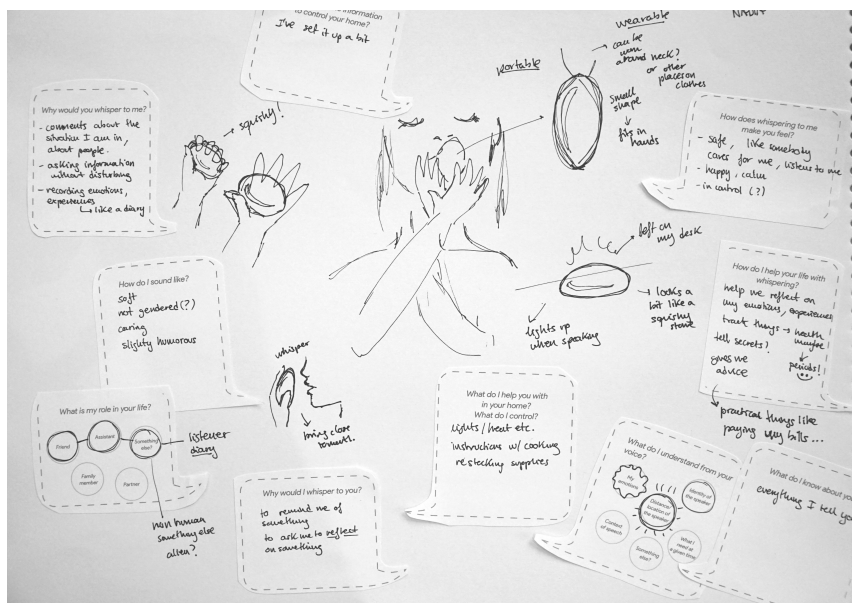

Figure 3. Participant's sketch of a voice assistant that helps you with reflecting on your emotions.

The design task made the participants reflect on what kind of qualities future voice assistants might have and how it would affect their relationship toward them. Some participants imagined voice assistants as pets or systems integrated into their homes that control their appliances. Others preferred a voice assistant that provides emotional support in a way of a 


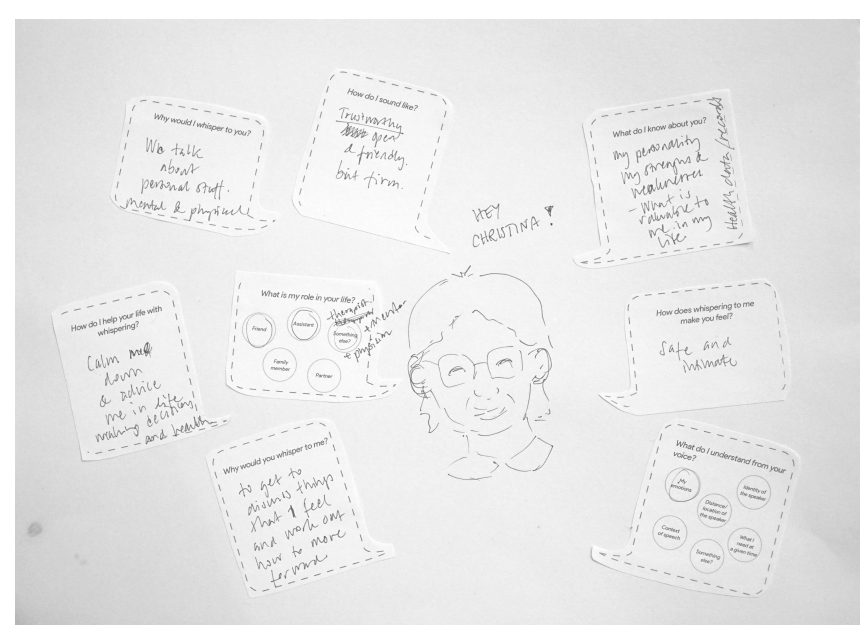

Figure 4. Participant's sketch of a voice assistant that is like a therapist and a good listener giving advice.

therapist or a good listener while still carrying the aesthetics of a device. The voice of the assistant was imagined as friendly, calm, and "human-like" while adapting to the users' emotional state that is being recognized through the user's voice modality. The participants did not express a preference in the gender of the assistant, however, one participant wished that her assistant would sound gender-neutral.

When asked How would your future home assistant help your life through whispering? some participants imagined it helping with "keeping private things private" (Nicklas), being discrete and not disturb people around you while interacting with the assistant. Others imagined it calming them down and adjusting to their emotional state like for example "making waking up less painful" (George), helping out with meditation, reflecting on personal issues (Figure 3) or acting as emotional support (Figure 4). For some of the participants controlling the house was a secondary feature, the primary one being a good friend that is also a good listener: "I didn't actually even think that it would control anything in my home but act more of a therapist or an advisor" (Susan, Figure 4). By reflecting on information that the user willingly gives out by being around the assistant, it would not only give advise on life and health but also reflect on the user's feelings, opinions, and choices in life: "I have difficulties making decisions in life so that would be a nice thing" (Kate). The results of the workshop made clear that the future of voice assistants was not necessarily in a home environment but the user's everyday life. Therefore, the focus of the assistant shifted from a home assistant to a portable voice assistant.

The amount of friendliness and personality that the assistant should express played a significant role in terms of how much information the user would be willing to share. "If it [the assistant] is more of a character and a human-like I would be less likely to share information with it. I guess I wouldn't trust it not to give out my information to someone else" (Nicklas), was a notion from the workshop describing the way humanlike qualities could even make us trust an assistant less. More machine-like features were preferred to reveal sensitive infor- mation to the assistant. However, to do that, it would also need to gain that role of a friend:"You don't share anything with people you're not friends with" (Nicklas). Together with friendliness also the role of the voice assistant could change from just an assistant to something more personal:"It's [the assistant] a person I would turn to, someone who is more like a part of my family" (Anna).

Finally, The last activity used the previous exercise as a starting point but dug deeper into specific possible scenarios with whispering voice assistants. In order to visualize the scenarios with a future assistant, the participants were then asked to pair up and imagine a situation with their future assistant that would require whispering. The concepts developed in the workshop were 1) whispering to a voice assistant during a dinner party to avoid disturbing others 2) keeping secrets, like planning a birthday party, from others (the assistant only speaks/reminds about the subject when the appropriate user is around), and 3 ) an assistant that you share an emotional and trusting bond with through whispering. The last one challenged the role of a voice assistant today and was, therefore, taken as a topic to further speculate through design fiction.

\section{Design Probe}

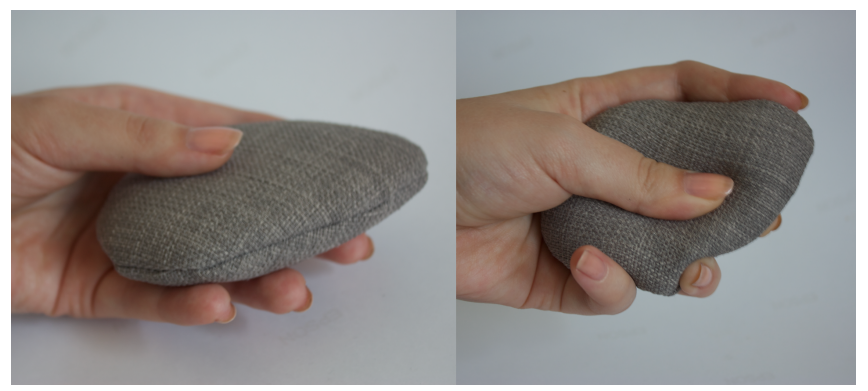

Figure 5. The handcrafted probe was designed to be portable and comfortable to hold and play with in your hand

To explore how people's relationship with a voice assistant would develop over time through whispering, we made a design probe [55] (Figure 5) based on the insights from the workshops, such as concepts and sketches (Figure 3-4). This probe followed the participants' vision of a good listener and advisor. It was crafted by covering it with a grey, slightly rough fabric to give it texture and filled with white sand and flour both to make holding and playing with it pleasant and relaxing similarly to a stress ball. Previous studies show how engaging users' interrelated bodily motions with, for example, fiddling properties can enhance focus and calm sensation [23, $24,25]$. This property was added based on the sketch from the workshop (Figure 4) but also to explore how it would affect the interaction. The design of the probe has similarities to Stane by Murray-Smith et al. [33], a hand-held interaction device controlled by tactile input. Despite its fictive properties, the probe could be possible to implement in high-fidelity by using similar hardware and allowing interaction through fiddling and voice.

As a way to gather inspirational insights on how people would interact with the probe and in which context, we recruited four participants; one participant from the previous co-speculation 
Table 2. Overview of the participants

\begin{tabular}{cccc}
\hline Pseudonym & Role & Nationality & Age \\
\hline Malin & Actress & SWE & 26 \\
Martin & $\begin{array}{c}\text { Urban } \\
\text { planner } \\
\text { Matilda }\end{array}$ & SWE & 31 \\
Marco & $\begin{array}{c}\text { Designer } \\
\text { HCI } \\
\text { researcher }\end{array}$ & SWE & 32 \\
& & & 42
\end{tabular}

workshop and three new participants (Table 2). All participants were familiar with voice assistants, and they were recruited by mutual connections with the first-author. We asked the participants to use the probe over a period of four days. This study resembled an experiment by Jeff Hawkins who mocked one of the first handheld, scaled-down computers with wood and paper; then carried it with him pretending it was a working device [19]. This simulated the core experience of having and using such device. We also asked the participants to record themselves with their smartphone while whispering to the probe when they felt that the context was right and they would benefit from the interaction (Figure 6). These recordings were later on sent back to the authors, together with answering a set of questions reflecting the way the probe was used. The recordings and reflective answers form our data.

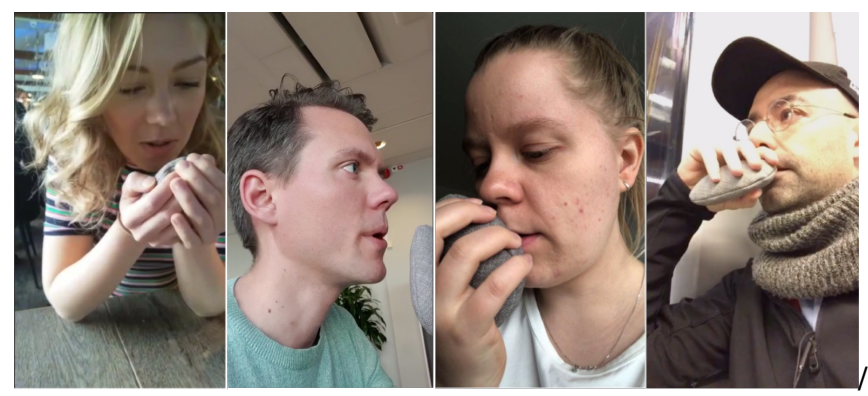

Figure 6. Malin, Martin, Matilda, and Marco using the design probe.

Our data shows that all of the participants carried the probe with them and three of the participants described bringing it to work or a dinner with friends. The probe was often placed on a nightstand or an office table and even brought to meetings at work. The participants carried their probe either in their bags or in their pockets and found themselves often treating it as a stress ball and playing around with it in their hands.

The recordings of the participants consisted of moments where they either used the probe in everyday situations where a full volume of voice was not appropriate like at work or when intentionally excluding others from the conversation. Malin used her probe to find out the ending to the new Avengers movie in a crowded cafe and Martin wished to be reminded of daily tasks while at work. Two other participants Matilda and Marco chose to use the probe as purely a personal support when asking for encouragement or reflection. Matilda recorded herself asking the assistant to wish her good luck while Marco recapped his thoughts and feelings while commuting.
Despite the short duration of the experiment, one of the participants, Martin, named his assistant and two wished it could be personalized more with different colors. A name that was brought up "Pebble" was not directly human-like but still reflected that the participant gave the probe certain characteristics and personality. The name was also essential to set to match the size of the assistant. Calling a small and soft looking probe "a pebble" made more sense than a name describing something big and strong.

\section{THE ONE: DESIGN FICTION SHORT FILM}

Following the workshop and probe, we created a short film One [37]. The film had several aims; 1) to synthesize and represent the qualitative data gathered in the workshops and by the probes, 2) to further speculate on the design and interactions of a whispering voice assistant, and 3) to anticipate the relations a whispering assistant could mediate with a user and the experiential qualities this could bring.

Note: Before reading further, we recommend watching the short film One in the supplementary material or online [37].

The film illustrates the daily life of the protagonist Andrea and how she uses whispering to interact with her voice assistant. The first scene (Figure 7) explores how whispering could be used to maintain a calm environment at home; inspired by a workshop participant's quote "It would be more pleasant to wake up if the assistant would whisper to me" (George). Here, whispering carries an implicit property when used to correspond to another calm state: switching on a calm, smaller light instead of a bright ceiling light. These scenes also explore the way the assistant would be placed according to the users. Martin explained how he placed the probe where ever he would usually place his phone: by his bed, in his pocket or bag. The protagonist, therefore, sleeps next to her assistant and takes it with her wherever she goes like it would be an embodied object instead of a device.

The following scenes explore the calming and helpful way that One contributes to the protagonist's life. First, when Andrea steps into the crowded subway, where she uses One to relieve anxiety (Figure 8). Andrea rubs One like a stress ball and together with that, the location, and the context of whispering, it triggers One to help her to calm down. After, One is used to seek for courage before an important meeting.

The journey of the day does not only represent the daily life of the protagonist but also the increased trust and change in the relationship to the assistant as time in her life goes by. The storytelling of the film changes rapidly from daily tasks such as being woken up by the assistant (George - an idea from the workshop), turning on the lights to seeking support (Matilda, Marco - an idea from the design probe), asking for advice on life's hard questions, and receiving help in decision making (an idea from speculative discussion during the workshop). As the plot evolves, so does the protagonist's need to rely on the assistant. The scenes were chosen based on the results from the workshop and probe experiment. The way the plot evolves into decision making for the user is speculation based on intimacy and trust expressed by the participants of the workshop and probe experiment. 




Figure 7. Still shot from the film where Andrea is woken up by One in the morning.

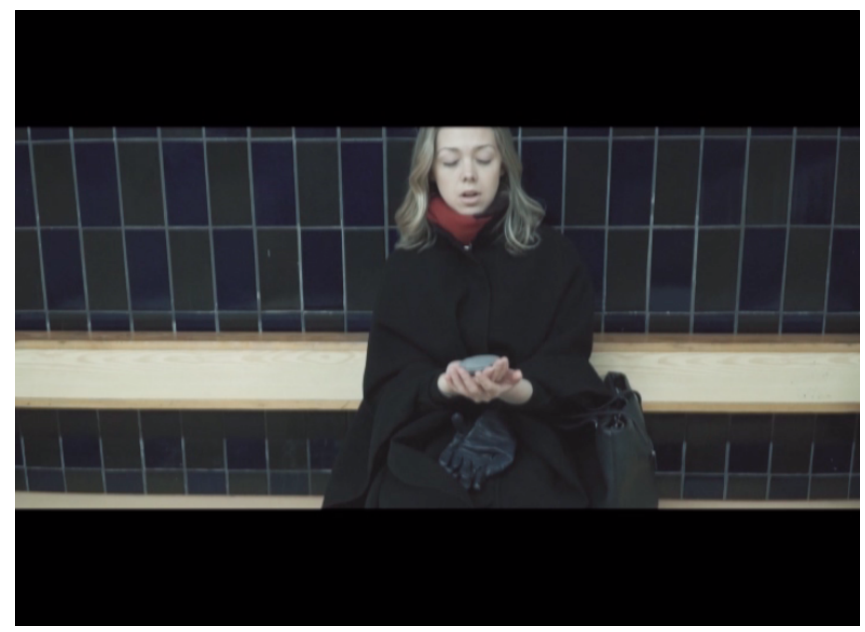

Figure 8. Still shot from when One helps Andrea to relieve anxiety.

\section{THE SHORT FILM: ANALYSIS}

Short films have previously been used to speculate on technological mediations between human and things [36], and as part of advocacy and challenging social norms for voice interaction $[45,50]$. We build on these approaches with a particular focus on crafting a plot where the protagonist's values and emotions evolve throughout the film in correspondence with intensified interactions with the voice assistant. We agree that the plot of the film is narrow, in the sense that it only visualises one out of all possible futures with whispering voice assistants but we hope it is inspirational for other researchers to speculate on them in ways different from the plot that we narrated. Whereas other short films have been analyzed through conducting interviews with experts about their reaction to the film [45], we analyze our short film through critical analysis as demonstrated in Bardzell et al.'s reading of another design fiction [3], with a particular focus on the aesthetic, personal and social values. Analyzing our short film through hermeneutic reading allows us to unfold the knowledge produced through our RtD process. We will first analyze the specific aesthetic qualities represented in the film, after which we abstract intermediate knowledge on the dimensions and experiential qualities of whispering, which will be presented in the following section.

\section{Aesthetics of One}

The assistant was named One in order to reflect the qualities of a machine and not a human but also personality and trust since it should be "the one" in your life that you can trust and share your inner feelings with. In the film we used the design probe as a prop, since participants in the probe study appreciated the soft tactile and slightly heavy feeling of the probe in their hands. Whereas the purpose of the probe was to elicit responses from participants and therefore should be designed "open" and "ambiguous", the prop in the film should appear believable in the context of a possible future; thus we worked with after effects to refine the object's visual character. One is designed with a soft, stone-looking texture that together with the oval shape draws on characteristics of nature, providing a comforting and an inviting look. One communicates through vibrant light and vibration on its surface. The syncing light of One is warm and a way for One to indicate speech and movement like when assisting the protagonist with meditation.

The voice of One was designed to be calm, encouraging but also, based on insights from the workshop, gender-neutral. This neutral-sounding voice challenges stereotypes of a female assistant and was achieved by altering the pitch of a female voice from $168 \mathrm{~Hz}$ to $153 \mathrm{~Hz}$ which is perceived as a neutral frequency for voice [40]. Conversely, it is up to an individual to decide what they find calming. A quiet, female vocalization, that does not directly indicate negative emotions through a scream or a shout, is here perceived calming for the protagonist.

\section{Aesthetics of the Short Film}

Throughout the story, Andrea was often filmed from above, highlighting her vulnerable position in life, making her feel small to the viewer. The background music and the blue overlay of the film also form a calming but melancholic environment for the story to take place in. The aesthetics of the film is sought to build on people's previous experience with science fiction, such as the Netflix series Black Mirror and Spike Jones' Her. Common for these two examples is their portrayal of futures that are neither completely utopian nor dystopian. Instead, the technology becomes a driver of the plot, highlighting both the desires and concerns with technology-driven futures.

\section{The Plot}

The possible future portrayed in the short film is the ability of the voice assistant to recognize the protagonist's needs and emotions and respond according to whispering, the implicit meaning behind it and the content of speech. The protagonist's narrative changes from using whispering to control devices to asking life advice. Whispering allows the protagonist to reveal deep emotions without anyone hearing it, and this is what allows her to share her thoughts and deepest feelings without feeling shame. This could lead One to gain more and more trust from the protagonist as the day goes by. The way whispering takes place in the context of the narrative relates either to the physical environment or the emotional state of 
Andrea. Whispering in public places such as the metro station allows excluding strangers from a conversation and in private space grants expression of anxiety, uncertainty, and possible shame.

The social and contextual consequences that can be apprehended from the film portray mainly the protagonist's private domain where whispering plays clearly a positive role for her. We notice how whispering induces social connectedness between Andrea and One and creates a sense of togetherness. As we focused on the private relation with an assistant, it is difficult to discuss the consequences of whispering in a public domain or involving several users, but we speculate that it could be more problematic. Whispering is an 'in-group'signal that can cause those, who are not socially included in the conversation, feel rejected, awkward or self-conscious.

\section{WHISPERING WITH VOICE ASSISTANTS}

Whispering is a new voice modality within voice interaction, and little is known about how it changes our use and experiences of voice assistants. We chose to use the method of design fiction to explore whispering, because of design fiction's speculative capabilities to imagine and externalize worlds and the sociotechnical relations within this world. Our design fiction is critical in the way that whispering challenges the normative use of voice assistants, questioning our perceived conceptual model of what a voice assistant is and how we experience it. And it is speculative in the way that our design fiction speculates on an alternative possible future where whispering with voice assistants is socially acceptable in private as well as public space and the potential consequences of this.

Our design-led inquiry into whispering contributes with dimensions and experiential qualities of whispering. The dimensions and experiential qualities have evolved through our RtD process: evoked through our autoethnographic experiences, expressed by the participants in the workshop and synthesized in the final short film which was critically analyzed by the authors. As knowledge contributions, the dimensions and experiential qualities are not meant to be viewed as universal guidelines for the design of voice assistants, but as analytic, anticipatory and generative concepts that can inspire further design and research into whispering voice assistants.

\section{Dimensions of Whispering}

The dimensions of whispering propose new possibilities for what, how and where people can interact with their voice (Table 3). Whereas these dimensions may appear to be mainly of functional use, they are intimately interwoven with and cannot be separated from the experiential qualities.

\section{Excluding Others from a Conversation}

A motivation for communicating information through whispering can be the secretive property of that information. This was a notion that the participants mentioned during the workshop through a discussion and sketches (Figure 3). People often tell secrets to each other that they do not wish others to hear or communicate passwords or personal information to company officials. The way whispering allows communicating this confirmation confidentially must be taken into consideration and the respond carefully designed. When requesting
Table 3. Overview of dimensions

\begin{tabular}{|c|c|}
\hline Dimension & Description \\
\hline $\begin{array}{l}\text { Excluding others from a } \\
\text { conversation }\end{array}$ & $\begin{array}{l}\text { With private content, } \\
\text { response through } \\
\text { whispering, sound or light }\end{array}$ \\
\hline User identity & $\begin{array}{l}\text { Recognise the user } \\
\text { identity }\end{array}$ \\
\hline State change & $\begin{array}{l}\text { Whispering responds with } \\
\text { a calm state change }\end{array}$ \\
\hline Avoiding disturbance & $\begin{array}{l}\text { Responds with whispering } \\
\text { or sound/light when the } \\
\text { environment requires calm } \\
\text { communication }\end{array}$ \\
\hline $\begin{array}{l}\text { Information of an } \\
\text { embarrassing nature }\end{array}$ & $\begin{array}{l}\text { To avoid embarrassment } \\
\text { when searching for } \\
\text { information }\end{array}$ \\
\hline $\begin{array}{l}\text { Adapting voice modality } \\
\text { to the user's voice }\end{array}$ & $\begin{array}{l}\text { Voice assistant should } \\
\text { adapt to the user's volume } \\
\text { and tone of voice }\end{array}$ \\
\hline
\end{tabular}

private content through whispering, like the balance of a bank account, a voice assistant's auditory respond needs to match whispering. On other occasions, response and feedback output could be forwarded, for example, through sound or light when a vocal response is not needed. Whispering information to the voice assistant could also cause it storing that information to a private file that could only be accessed by that user. Whispering to a voice assistant to exclude others from a conversation might be perceived as rude by people in close proximity, and the social norms around this should be closely studied in the local context.

\section{User Identity}

Whispering has the potential to create more data on user identity. It is critical for voice technology to recognise the identity of the person speaking and react according to that received information. Private information like meetings, passwords, or other personal information should not be revealed to a third-party, also not when the request is initiated with whispering. Correct identity recognition can become crucial for maintaining trust toward a voice assistant. During the workshop, participants expressed this dimension through sketches where the voice assistant would only reveal secrets to the user that initially spoke them.

\section{State Change}

Whispering together with other meta-data, such as time of the day, has the potential to reveal information about a context of use. Through RtD process and discussions among it, it came up that the function that a user wants to carry out, using the voice assistant, can be aligned to the proposed context. This includes various state changes in an atmosphere such as lighting or music. Whispering can correspond to switching on dimmed lights instead of bright ones or turning on soft music instead of loud one to preserve the calm environment.

\section{Avoiding Disturbance}

Whispering can also be used to send private messages or request actions by the assistant in an environment where it would be inconvenient to use the full volume of your voice. These 
instances are, for example, a work environment or a dinner party where noise or the interruption of another person would be considered rude. A response could be forwarded through whispering or a sound/light output. This dimension was initiated through a workshop sketch where a voice assistant was used while participating a loud dinner party.

\section{Information of an embarrassing nature}

As stated during the workshop - the uncomfortable feeling of embarrassment can be avoided by instead, whispering it to a device. A response could be forwarded through whispering. Concealing embarrassing questions or information through whispering will potentially reproduce that the topic is perceived as embarrassing. Thus, it is important for designers to questions why the specific topic is embarrassing in their context and whether that should potentially be challenged.

\section{Adapting voice modality to the user's voice and mood}

The participants of the workshop mentioned how voice technology today does not adapt nor match to the user's voice modality or the mood that can be interpreted from the voice. We hardly whisper when we are angry or upset but rather sad, afraid or tired. Therefore, whispering could follow a soft, understanding response from the assistant to adapt to the tone and mood of the user.

\section{Experiential Qualities of Whispering}

Our research shows that whispering creates new experiences of interacting with voice assistants. In this section, we articulate and discuss properties that characterize a user's experience of interacting through whispering. We name these the experiential qualities of whispering [30]. The experiential qualities of whispering articulate feelings, emotions and affective experiences, which respond to and are equally important to instrumental ideals.

\section{Creepiness}

One of the experiential qualities of interacting with a voice assistant through whispering is a feeling of creepiness. The assistant can be perceived as creepy because the voice modality of whispering breaks with our social norms and expectations of voice interaction. Whispering is not significantly represented in sociotechnical imaginaries of voice interactions, partly because it has not been researched and because it is not represented in popular science fiction (with the exception of Spike Jones' science fiction movie "Her"). Thus whispering exists outside what people might find desirable or possible, consequently producing feelings of creepiness.

Within HCI, user experiences of creepy technology have been studied from the perspective of smartphone tracking [49] and smart home security cameras [38]. These previous studies draw attention to how privacy and security issues can make technologies seem creepy. When our participants in the workshops were initially reacting to the sound of a whispering Amazon Alexa, several participants described whispering as creepy. This includes if a voice assistant whispers in the wrong context. What is a right or wrong context of whispering is a sociocultural question, but the participants explained that whispering is creepy when it is socially or contextually not necessary or a norm, e.g. when whispering even though no one else is around when there is no need or when whispering a laugh. Another example of when whispering was found creepy was when whispering at night or early in the morning because whispering at this time of the day could amplify an already fearful time of the day that involves darkness.

The more detailed voice modalities that designers add as features, the more likely people are to find a resemblance of human-likeness in voice assistants. Empathy, being one of the essential qualities that designers aim to facilitate. Yip et al. [56] point out how technology is understood as creepy when it reaches a threshold of human-likeness and falls into an uncanny valley. Humans couple whispering to a human body [27]. Interacting with a voice assistant through whispering thus prompts attributions of human-likeness [9], and as human bodies are seldom ascribed to robots [13], this mismatch causes a feeling of creepiness [14].

Following this related work on creepy technologies, creepiness is an experiential quality that characterizes a variety of experiences; either relating to social norms, human-likeness or privacy and security threats. In whispering voice assistants, creepiness is an experiential quality that designers may not to facilitate (unless they are designing jokey functions or Easter eggs), but as social norms and perceptions of voice assistants are still developing, creepiness can be an undesirable experiential quality arising through use. To work away from experiences of creepiness, designers may more carefully attune to current social norms, demystify the technology behind the whispering, and secure data privacy and security for the user.

\section{Intimacy}

The second experiential quality of whispering, that we found in our design research into whispering, is the quality of intimacy. Whispering affords a sense of closeness to a voice assistant since whispering can only be used within an intimate reception by the ear [27]. Similarly, our voice assistant One was designed to be handheld and carefully stroked, creating feelings of intimacy. When the participants were to think about whispering to their future voice assistants they expressed it would make them feel safe, calm, cared for, and intimate.

In HCI, intimacy has been concerned with physical togetherness [15]. For voice assistants, physical togetherness arises in the shared space where a user and a voice assistant are in close proximity and where their voices meet. Although a voice assistant is only physically present in the form of a speaker (integrated into a smart speaker, computer, smartphone, a TV, or in our case a soft "stone") the voice of the assistant fills up the room. Whispering affords that the shared space shrinks, as the assistant and user get closer. In the short film, the protagonist lets her voice assistant share the public and domestic space with her. Close proximity, when whispering with the assistant, encourages 'presence', strengthening the feeling of intimacy and a sense of empathy and being understood. Being physically and emotionally close with One allows the protagonist to share emotions and vulnerable thoughts with someone that can be considered as essential for the health and well-being of everyday life. One of the essential elements for improving a sense of intimacy is the communication of emotions [21]. 
When a person has a high degree of intimacy with a device they can communicate ideas and emotions effectively through the device as if it were an extension of themselves [10]. In our whispering voice assistant, a user is experiencing the voice assistant in an intimate way as they move closer, share a smaller intimate space and communicate emotions and secretary information. In human-human interaction whispering communicates emotions like intimacy [27]. For corporations, like Google and Apple etc, one of the key qualities, that they aim to facilitate through their algorithmic assistants, is intimacy [11]. Our research shows that intimacy can arise in whispering interactions between a human and a voice assistant.

The experimental quality of intimacy allows a technology to digitally store and process large amounts of information about behavior and emotions. For the technology market, it is very useful to find out what consumers feel and think but this can cause several political and ethical discussions among the topics of intimate technology and data sharing. Designing intimacy needs to involve the protection of the physical and mental integrity of users. Even though intimacy as an experiential quality can be useful to designers in terms of strengthening experiences and supporting health, it can be seen as a contradiction in terms of connection to lifeless devices.

\section{Trust}

The third experiential quality of whispering is a feeling of trust. Trust has been proposed to be a critical element in conversational interfaces $[8,45]$, and something that designers should strive to facilitate through interactions [50]. Our research supports these previous studies by showing how whispering can facilitate experiences of trust. Participants imagined that their future whispering assistant made them feel safe and that it would be something that they can trust. In the short film, we manifested this feeling through the experiences that our protagonists Andrea has with her voice assistant. Trust in voice assistants can be defined as the willingness to become vulnerable in interacting with them; e.g. in sharing private information, accepting the information provided by them, or following their suggestions [8]. Issues around trust in voice assistants arise when voice assistant's credibility is questioned, or when users are unsure how their data would be treated and what data is collected. Our design fiction does not tap into these questions of trust; instead, we follow Andrea "blindly" trusting her assistant, not questioning the privacy of her data or the assistant's credibility. As trust is a social construct, deeply shaped by contextual and personal factors, we did not aim to provide any definitions or measures for how trust is enabled, neither can we conclude that whispering will inevitably enable trust. However, our research project has inquired on whispering as an experience that is eliciting trust, and our design fiction short film portrays possible positive experiences of this.

\section{DISCUSSION}

The results and contributions of this RtD project consist of the particular design artefact (the whispering voice assistant), the design fiction short film, and the dimensions and experiential qualities of whispering. The dimensions and experiential qualities of whispering are ways to annotate the RtD project and conceptualise how this specific and particular RtD project can become generative and inspirational for other design researchers [12]. The experiential qualities characterize the experiences a user might get when interacting with a voice assistant through whispering. They are intended to be evocative and contribute to richer, more novel interactions with voice assistants. Whereas intimacy and trust are experiential qualities that designers should strive to facilitate through their design, creepiness is an experiential quality that is often a less desirable bi-product of whispering, though hard to exclude due to the shifting social norms and acceptance of voice assistants. In referring to Löwgren's concept of experiential qualities [30], it is crucial to state that a designer cannot design intimate voice assistants, or voice assistants that possess the quality of trust. Instead, designers can design to increase the chances that the use of the voice assistants will be experienced in a certain intimate and trustworthy way [30]. We hope that other design researchers can build on and challenge the experiential qualities of creepiness, intimate and trust, in voice interactions characterised by whispering or beyond. These experiential qualities have evolved from the material-specific aesthetics of using voice to interact with computers. As voice assistants are rapidly developed in industry and adopted by end-users, we argue that it is crucial to construct knowledge concerning the aesthetics of voice interaction design. The design fiction and the experiential qualities of whispering, presented in this paper, are one such knowledge contribution.

\section{CONCLUSION}

In this paper, we presented a RtD project exploring whispering with voice assistants. The research project included an auto-ethnographic experiences with Amazon Alexa and Google Home, a co-speculation workshop, the use of a probe as well as a design fiction short film One. Our argument for this research is the need to better understand how whispering can change and shape how designers design voice assistants and how whispering affects the user of the voice assistant. The design fiction short film presented in this paper particularises a novel way to communicate with a voice assistant, speculating on the experiences and aesthetics of whispering and how whispering could change the human-computer relation. We contributed with dimensions of whispering, closer to instrumental ideals, and experiential qualities, closer to the aesthetics of interaction. The design fiction short film raises several open-ended questions relating to the experiential qualities, such as: What are the limits to how human-like we want our technologies to be, and how close we want to be with them? Can the trust created by an increased sense of empathy from technologies be beneficial to a user, or are we doomed to rely on technology even more in the future? What does this mean to our freedom of choice and expression? These questions are hardly resolved by this research but instead addressed for future speculations to be explored and evaluated in RtD and empirical studies.

\section{ACKNOWLEDGEMENTS}

Our deepest thanks to the participants and Karoline Furberg for acting in the video. This research was supported by 2017 05133, Swedish Foundation for Strategic Research project. 


\section{REFERENCES}

[1] Tawfiq Ammari, Jofish Kaye, Janice Y Tsai, and Frank Bentley. 2019. Music, Search, and IoT: How People (Really) Use Voice Assistants. ACM Transactions on Computer-Human Interaction (TOCHI) 26, 3 (2019), 17.

[2] Till Ballendat, Nicolai Marquardt, and Saul Greenberg. 2010. Proxemic interaction: designing for a proximity and orientation-aware environment. In $A C M$ International Conference on Interactive Tabletops and Surfaces. ACM, 121-130.

[3] Jeffrey Bardzell, Shaowen Bardzell, and Lone Koefoed Hansen. 2015. Immodest proposals: Research through design and knowledge. In Proceedings of the 33 rd Annual ACM Conference on Human Factors in Computing Systems. ACM, 2093-2102.

[4] Mark Blythe. 2017. Research Fiction: Storytelling, Plot and Design. In Proceedings of the 2017 CHI Conference on Human Factors in Computing Systems (CHI '17). ACM, New York, NY, USA, 5400-5411. DOI : http://dx.doi.org/10.1145/3025453.3026023

[5] Herbert H Clark. 1996. Using language. Cambridge university press.

[6] Audrey Desjardins, Jeremy E. Viny, Cayla Key, and Nouela Johnston. 2019. Alternative Avenues for IoT: Designing with Non-Stereotypical Homes. In Proceedings of the 2019 CHI Conference on Human Factors in Computing Systems (CHI '19). ACM, New York, NY, USA, Article 351, 13 pages. DOI : http://dx.doi.org/10.1145/3290605.3300581

[7] Stefania Druga, Randi Williams, Cynthia Breazeal, and Mitchel Resnick. 2017. "Hey Google is It OK if I Eat You?": Initial Explorations in Child-Agent Interaction. In Proceedings of the 2017 Conference on Interaction Design and Children (IDC '17). ACM, New York, NY, USA, 595-600. DOI : http://dx.doi.org/10.1145/3078072.3084330

[8] Justin Edwards and Elaheh Sanoubari. 2019. A Need for Trust in Conversational Interface Research. In Proceedings of the 1st International Conference on Conversational User Interfaces (CUI '19). ACM, New York, NY, USA, Article 21, 3 pages. DOI : http://dx.doi.org/10.1145/3342775.3342809

[9] Nicholas Epley, Adam Waytz, and John T Cacioppo. 2007. On seeing human: a three-factor theory of anthropomorphism. Psychological review 114, 4 (2007), 864.

[10] Sidney Fels. 2000. Intimacy and embodiment: implications for art and technology. In Proceedings of the 2000 ACM workshops on Multimedia. ACM, 13-16.

[11] Ed Finn. What Algorithms Want: Imagination in the Age of Computing (reprint edition ed.). MIT Press.

[12] William Gaver. 2012. What should we expect from research through design?. In Proceedings of the SIGCHI conference on human factors in computing systems. ACM, 937-946.
[13] Heather M Gray, Kurt Gray, and Daniel M Wegner. 2007. Dimensions of mind perception. science 315 , 5812 (2007), 619-619.

[14] Kurt Gray and Daniel M Wegner. 2012. Feeling robots and human zombies: Mind perception and the uncanny valley. Cognition 125, 1 (2012), 125-130.

[15] Konstantinos Grivas. 2006. Digital Selves: Devices for intimate communications between homes. Personal and Ubiquitous Computing 10, 2-3 (2006), 66-76.

[16] Edward Twitchell Hall. 1910. The hidden dimension. Vol. 609. Garden City, NY: Doubleday.

[17] Edward T Hall, Ray L Birdwhistell, Bernhard Bock, Paul Bohannan, A Richard Diebold Jr, Marshall Durbin, Munro S Edmonson, JL Fischer, Dell Hymes, Solon T Kimball, and others. 1968. Proxemics [and comments and replies]. Current anthropology 9, 2/3 (1968), $83-108$.

[18] Mizuki Hisaka. 2018. Amazon Alexa Will Now Whisper Back To You, But Some People Find It 'Creepy'. (2018). Retrieved Aug 20, 2019 from https:

//www.inquisitr.com/5123302/amazon-alexa-will-nowwhisper-back-to-you-but-some-people-find-it-creepy/

[19] David S. Jackson. 1998. Palm-To-Palm Combat. (1998). Retrieved September 19, 2019 from http://content.time.com/time/magazine/article/ 0,9171,987979,00.html

[20] Lars-Erik Janlert and Erik Stolterman. 2015. Faceless Interaction-A Conceptual Examination of the Notion of Interface: Past, Present, and Future. Human-Computer Interaction 30, 6 (2015), 507-539.

[21] Joris H Janssen, Jeremy N Bailenson, Wijnand A IJsselsteijn, and Joyce HDM Westerink. 2010. Intimate heartbeats: Opportunities for affective communication technology. IEEE Transactions on Affective Computing 1, 2 (2010), 72-80.

[22] Wendy Ju and Larry Leifer. 2008. The design of implicit interactions: Making interactive systems less obnoxious. Design Issues 24, 3 (2008), 72-84.

[23] Michael Karlesky and Katherine Isbister. 2014a. Designing for the physical margins of digital workspaces: fidget widgets in support of productivity and creativity. In Proceedings of the 8th international conference on tangible, embedded and embodied interaction. ACM, 13-20.

[24] Michael Karlesky and Katherine Isbister. 2014b. Fidget widgets: designing for the physical margins of digital workspaces. In Proceedings of the 8th International Conference on Tangible, Embedded and Embodied Interaction. ACM, 301-304.

[25] Michael Karlesky and Katherine Isbister. 2016. Understanding Fidget Widgets: Exploring the Design Space of Embodied Self-Regulation. In Proceedings of the 9th Nordic Conference on Human-Computer Interaction. ACM, 38. 
[26] Sunok Lee, Sungbae Kim, and Sangsu Lee. 2019. "What Does Your Agent Look Like?": A Drawing Study to Understand Users' Perceived Persona of Conversational Agent. In Extended Abstracts of the 2019 CHI Conference on Human Factors in Computing Systems (CHI EA '19). ACM, New York, NY, USA, Article LBW0143, 6 pages. DOI:

http://dx.doi.org/10.1145/3290607.3312796

[27] Xinghua Li. 2011. Whispering: the murmur of power in a lo-fi world. Media, Culture \& Society 33, 1 (2011), 19-34.

[28] Yong Yates Lin, Zhengyi Le, Eric Becker, and Fillia Makedon. 2010. Acoustical implicit communication in human-robot interaction. In Proceedings of the 3rd International Conference on PErvasive Technologies Related to Assistive Environments. ACM, 5.

[29] Mallory Locklear. 2019. Microsoft patent suggests you inhale whisper to your voice assistants. (2019).

Retrieved September 8, 2019 from

https://www.engadget.com/2019/01/03/microsoft-patentwhisper-voice-assistants/?

[30] Jonas Löwgren. 2007. Pliability as an experiential quality: Exploring the aesthetics of interaction design. Artifact: Journal of Design Practice 1, 2 (2007), 85-95.

[31] Andrés Lucero. 2018. Living Without a Mobile Phone: An Autoethnography. In Proceedings of the 2018 Designing Interactive Systems Conference (DIS '18). ACM, New York, NY, USA, 765-776. DOI: http://dx.doi.org/10.1145/3196709.3196731

[32] Trieuvy Luu, Martijn van den Broeck, and Marie Louise Juul Sondergaard. 2018. Data economy: interweaving storytelling and world building in design fiction. In 10th Nordic Conference on Human-Computer Interaction (NORDICHI). ACM Digital Library, 771-786.

[33] Roderick Murray-Smith, John Williamson, Stephen Hughes, Torben Quaade, and Steven Strachan. 2008. Rub the stane. In CHI'08 Extended Abstracts on Human Factors in Computing Systems. ACM, 2355-2360.

[34] Clifford Nass and Kwan Min Lee. 2000. Does computer-generated speech manifest personality? An experimental test of similarity-attraction. In Proceedings of the SIGCHI conference on Human Factors in Computing Systems. ACM, 329-336.

[35] Clifford Nass, Jonathan Steuer, and Ellen R Tauber. 1994. Computers are social actors. In Proceedings of the SIGCHI conference on Human factors in computing systems. ACM, 72-78.

[36] Doenja Oogjes and Ron Wakkary. 2017. Videos of Things: Speculating on, Anticipating and Synthesizing Technological Mediations. In Proceedings of the 2017 CHI Conference on Human Factors in Computing Systems (CHI '17). ACM, New York, NY, USA, 4489-4500. DOI :

http://dx.doi.org/10.1145/3025453.3025748
[37] Emmi Parviainen and Marie Louise Juul Søndergaard. 2019. ONE. (2019). Retrieved Jan 8, 2020 from https://vimeo.com/383497295

[38] James Pierce. 2019. Smart Home Security Cameras and Shifting Lines of Creepiness: A Design-Led Inquiry. In Proceedings of the 2019 CHI Conference on Human Factors in Computing Systems. ACM, 45.

[39] Martin Porcheron, Joel E. Fischer, Stuart Reeves, and Sarah Sharples. 2018. Voice Interfaces in Everyday Life. In Proceedings of the 2018 CHI Conference on Human Factors in Computing Systems (CHI '18). ACM, New York, NY, USA, Article 640, 12 pages. DOI : http://dx.doi.org/10.1145/3173574.3174214

[40] Copenhangen Pride, Virtue, Equal AI, Koalition Interactive, and thirtysoundsgood. 2019. Meet Q The First Genderless Voice. (2019). Retrieved June 4, 2019 from http://www.genderlessvoice.com

[41] Pramila Rani, Nilanjan Sarkar, and Julie Adams. 2007. Anxiety-based affective communication for implicit human-machine interaction. Advanced Engineering Informatics 21, 3 (2007), 323-334.

[42] Erika Rawes. 2018. How to Enable Whisper Mode on Alexa. (2018). Retrieved March 13, 2019 from https://www.digitaltrends.com/home/how-to-enablewhisper-mode-on-alexa/

[43] Johan Redström. Making Design Theory. The MIT Press.

[44] Stuart Reeves. 2019. Conversation Considered Harmful?. In Proceedings of the 1st International Conference on Conversational User Interfaces (CUI '19). ACM, New York, NY, USA, Article 10, 3 pages. DOI: http://dx.doi.org/10.1145/3342775.3342796

[45] Jon Rogers, Loraine Clarke, Martin Skelly, Nick Taylor, Pete Thomas, Michelle Thorne, Solana Larsen, Katarzyna Odrozek, Julia Kloiber, Peter Bihr, and others. 2019. Our Friends Electric: Reflections on Advocacy and Design Research for the Voice Enabled Internet. In Proceedings of the 2019 CHI Conference on Human Factors in Computing Systems. ACM, 114.

[46] R. Murray Schafer. Soundscape: Our Sonic Environment and the Tuning of the World (original ed. edition ed.). Destiny Books.

[47] Albrecht Schmidt. 2000. Implicit human computer interaction through context. Personal technologies 4, 2-3 (2000), 191-199.

[48] Alex Sciuto, Arnita Saini, Jodi Forlizzi, and Jason I. Hong. 2018. "Hey Alexa, What's Up?": A Mixed-Methods Studies of In-Home Conversational Agent Usage. In Proceedings of the 2018 Designing Interactive Systems Conference (DIS '18). ACM, New York, NY, USA, 857-868. DOI : http://dx.doi.org/10.1145/3196709.3196772 
[49] Irina Shklovski, Scott D Mainwaring, Halla Hrund Skúladóttir, and Höskuldur Borgthorsson. 2014. Leakiness and creepiness in app space: Perceptions of privacy and mobile app use. In Proceedings of the $32 \mathrm{nd}$ annual ACM conference on Human factors in computing systems. ACM, 2347-2356.

[50] Marie Louise Juul Søndergaard and Lone Koefoed Hansen. 2018. Intimate Futures: Staying with the Trouble of Digital Personal Assistants through Design Fiction. In Proceedings of the 2018 Designing Interactive Systems Conference. ACM, 869-880.

[51] Yolande Strengers, Jenny Kennedy, Paula Arcari, Larissa Nicholls, and Melissa Gregg. 2019. Protection, Productivity and Pleasure in the Smart Home: Emerging Expectations and Gendered Insights from Australian Early Adopters. In Proceedings of the 2019 CHI Conference on Human Factors in Computing Systems (CHI '19). ACM, New York, NY, USA, Article 645, 13 pages. DOI : http://dx.doi.org/10.1145/3290605.3300875

[52] Selina Jeanne Sutton, Paul Foulkes, David Kirk, and Shaun Lawson. 2019. Voice As a Design Material: Sociophonetic Inspired Design Strategies in Human-Computer Interaction. In Proceedings of the 2019 CHI Conference on Human Factors in Computing
Systems (CHI '19). ACM, New York, NY, USA, Article 603, 14 pages. DOI:

http://dx.doi.org/10.1145/3290605.3300833

[53] Joshua Tanenbaum. 2014. Design fictional interactions: why HCI should care about stories. interactions 21,5 (2014), 22-23.

[54] Omer Tene and Jules Polonetsky. 2013. A theory of creepy: technology, privacy and shifting social norms. Yale JL \& Tech. 16 (2013), 59.

[55] Jayne Wallace, John McCarthy, Peter C. Wright, and Patrick Olivier. 2013. Making Design Probes Work. In Proceedings of the SIGCHI Conference on Human Factors in Computing Systems (CHI'13). ACM, New York, NY, USA, 3441-3450. DOI : http://dx.doi.org/10.1145/2470654.2466473

[56] Jason C Yip, Kiley Sobel, Xin Gao, Allison Marie Hishikawa, Alexis Lim, Laura Meng, Romaine Flor Ofiana, Justin Park, and Alexis Hiniker. 2019. Laughing is Scary, but Farting is Cute: A Conceptual Model of Children's Perspectives of Creepy Technologies. In Proceedings of the 2019 CHI Conference on Human Factors in Computing Systems. ACM, 73. 